\title{
Antiobesity Effect of Astilbe chinensis Franch. et Savet. Extract through Regulation of Adipogenesis and AMP-Activated Protein Kinase Pathways in 3T3-L1 Adipocyte and High-Fat Diet-Induced C57BL/6N Obese Mice
}

\author{
Xian Hua Zhang $\mathbb{D}^{1}$, Zhiqiang Wang, ${ }^{2}$ Bueom-Goo Kang, ${ }^{3}$ Seung Hwan Hwang, \\ Jae-Young Lee, ${ }^{4}$ Soon Sung Lim $\mathbb{D}^{3},{ }^{3}$ and Bo Huang ${ }^{1}{ }^{1}$ \\ ${ }^{1}$ Department of Food Science and Engineering, Jinzhou Medical University, Jinzhou 121001, China \\ ${ }^{2}$ College of Public Health, Hebei University, Baoding, 071002, China \\ ${ }^{3}$ Department of Food Science and Nutrition, Hallym University, Hallymdeahak-gil, Chuncheon 24252, Republic of Korea \\ ${ }^{4}$ Department of Biochemistry, School of Medicine, Hallym University, Hallymdehak-gil, Chuncheon 24252, Republic of Korea
}

Correspondence should be addressed to Soon Sung Lim; limss@hallym.ac.kr and Bo Huang; huangbo2005@naver.com

Received 17 July 2018; Revised 10 November 2018; Accepted 18 November 2018; Published 9 December 2018

Academic Editor: Toshiaki Makino

Copyright (c) 2018 Xian Hua Zhang et al. This is an open access article distributed under the Creative Commons Attribution License, which permits unrestricted use, distribution, and reproduction in any medium, provided the original work is properly cited.

\begin{abstract}
Astilbe chinensis Franch. et Savat. (AC) has been used in traditional medicine for the treatment of chronic bronchitis, arthralgia, and gastralgia. In this study, we investigated the antiobesity effect of AC extract on 3T3-L1 preadipocytes and high-fat-diet-fed C57BL/6N obese mice. We found that AC extracts dramatically decreased the lipid content of 3T3-L1 cells in a concentrationdependent manner without cytotoxicity. The action mechanism of AC extract was demonstrated to be the inhibition of lipid accumulation and dose-dependent decrease in the expression of CCAAT/enhancer-binding protein $\alpha(\mathrm{C} / \mathrm{EBP} \alpha)$, peroxisome proliferator-activated receptor- $\gamma$ (PPAR- $\gamma$ ), and sterol regulatory element-binding protein 1 (SREBP1). Furthermore, AC extract increased the mitochondrial phosphorylation of AMP-activated protein kinase (AMPK) and acetyl-CoA carboxylase (ACC), mitochondrial biogenesis, and lipolysis-related factors. In amice model of high-fat-diet-induced obesity, the mice administered AC extract experienced significant decrease of $64 \%$ in weight gain, $55 \%$ in insulin resistance index, $22 \%$ in plasma triglycerides (TG), $56 \%$ in total cholesterol (TC), and 21\% in nonesterified fatty acid (NEFA) levels compared with those in the high-fat diet-fed control mice. Collectively, these results indicated that AC extract exerted antiobesogenic activity through the modulation of the AMPK signaling pathway, inhibition of adipogenesis, decreased lipid content, and reduced adipocyte size.
\end{abstract}

\section{Introduction}

The increased incidence of obesity, which is associated with the increased intake of calorie-rich food and a sedentary lifestyle, has become a global health problem over the last 40 years. Obesity increases the risk of type 2 diabetes mellitus, hypertension, dyslipidemia, and cardiovascular disease, which all reduce life expectancy $[1,2]$. Obesity is major health burden, with annual costs exceeding $\$ 100$ billion $[3,4]$. The World Health Organization has identified obesity as one of the major emerging chronic diseases of the 21st century. Many researchers and companies have therefore undertaken the development of therapies to control obesity. The Food and Drug Administration (FDA) has approved a number of antiobesity agents that act on the central nervous system, such as orlistat, lorcaserin, and phentermine/topiramate (Qsymia) [5]. These drugs can produce adverse effects, including pulmonary hypertension, cardiovascular toxicity, stroke, nonfatal cardiovascular events, and neuropsychiatric issues [6]; therefore, the plant kingdom has emerged as a popular resource for natural effective weight loss drugs that have a broad range of action and minimal or no adverse effects.

Astilbe chinensis Franch. et Savat. (AC), a member of the Saxifragaceae family, is a perennial herbaceous plant that grows at an altitude of 390-3600 m in Russia, China, Korea, 
and Japan $[7,8]$. In traditional medicine, its rhizome has been used to treat chronic bronchitis, arthralgia, headache, and gastralgia [9]. Pharmacological experiments have demonstrated the antineoplastic and immunopotentiating activities of extracts from AC [8], such as flavonoids, steroids, and triterpenoids [10]. However, there are no reports documenting the antiobesity effect of AC. In the present study, we evaluated the effects of AC extract on 3T3-L1 preadipocyte differentiation and investigated its underlying effect on body weight gain, lipid droplet accumulation, lipolysis, and gene expression in high-fat-diet-fed obese C57BL/6N mice.

\section{Materials and Methods}

2.1. Preparation of AC Extract. The whole plant of AC extract was purchased from Gangwon Medicinal Herbs (Chuncheon, South Korea) and authenticated by Professor-Heung Jun Chi, a medicinal botanist. The dried AC $(1.0 \mathrm{~kg})$ was extracted by $30 \%$ ethanol-water solution $(\mathrm{v} / \mathrm{v})$ (10 liters) at $70^{\circ} \mathrm{C}$ for 6 hours (h). The extract was filtered using filter paper and concentrated under a vacuum evaporator. The concentrated extracts were freeze-dried by PVTED10R (Ilshinbiobase Co., Ltd., Yangju, Korea).

\subsection{High Performance Liquid Chromatography (HPLC) Analy-} sis of AC Extract. HPLC equipment was an Agilent technologies 1200 series system and the chromatographic separations were performed using a Gemini column $(150 \times 4.6 \mathrm{~mm}$ i.d., $5 \mu \mathrm{m}$ particle size; Phenomenex). The mobile phase consisted of solvents A ( $0.1 \%$ aqueous trifluoroacetic acid) and $\mathrm{B}$ (acetonitrile). The gradient elution was modified as follows: from 0 to $10 \mathrm{~min}, 0-20 \% \mathrm{~B}$; from $10-15 \mathrm{~min}, 20-20 \%$ B; from $15-25 \mathrm{~min}, 20-25 \% \mathrm{~B}$; from $25-35 \mathrm{~min}, 25-30 \% \mathrm{~B}$; from $35-40 \mathrm{~min}, 30-30 \% \mathrm{~B}$; from $40-50 \mathrm{~min}, 30-100 \% \mathrm{~B}$. A flow rate was $1 \mathrm{~mL} / \mathrm{min}$, and injection volume was $10 \mu \mathrm{L}$. UV detected at $280 \mathrm{~nm}$. Determinations for triterpenoids of Astilbe chinenesis extracts were performed according to the methods by Moon et al. [9].

2.3. 3T3-L1 Preadipocyte Differentiation and Oil Red O Staining. The 3T3-L1 preadipocyte cell were obtained from the ATCC, and was grown in DMEM medium containing 10\% fetal bovine serum (FBS), $100 \mathrm{U} / \mathrm{mL}$ of penicillin, and 100 $\mu \mathrm{g} / \mathrm{mL}$ of streptomycin at $37^{\circ} \mathrm{C}$ under $5 \% \mathrm{CO}_{2}$. On 2 days after confluence, preadipocytes of 3T3-L1 cell (day 0) were cultured in differentiation medium (DMEM containing 1 $\mu \mathrm{M}$ dexamethasone, $0.5 \mathrm{mM}$ 3-isobutyl-1-methylxanthine, 10 $\mu \mathrm{g} / \mathrm{mL}$ insulin, and $10 \% \mathrm{FBS}$ ) for 4 days, then switched to post differentiation medium containing $10 \%$ FBS and $10 \mu \mathrm{g} / \mathrm{mL}$ insulin, and then changed to $10 \%$ FBS medium for an additional 2 days to induce differentiation. After differentiation was induced, the 3T3-L1 adipocytes were stained with fresh Oil Red O solution. The 3T3-L1 adipocytes were washed with phosphate buffered saline (PBS) and fixed with $10 \%$ formalin. After Oil Red O stain, the cells were photographed using a phase-contrast microscope (Olympus CKX41, Tokyo, Japan) and the lipid droplets were dissolved in isopropanol and quantified by a microplate reader (SYNERGY H1, Microplate reader, BioTek, USA) at $540 \mathrm{~nm}$.
TABLE 1: Composition of the experimental diets.

\begin{tabular}{lcc}
\hline Component (g/kg) & RD & HFD \\
\hline Casein & 210 & 265 \\
L-cystine & 3 & 4 \\
Corn starch & 280 & - \\
Maltodextrin & 50 & 160 \\
Sucrose & 325 & 90 \\
Lard & 20 & 310 \\
Soybean oil & 20 & 30 \\
Cellulose & 37.15 & 65.5 \\
Mineral mixture & 35 & 48 \\
Vitamin mixture & 15 & 21 \\
Calcium phosphate, dibasic & 2 & 3.4 \\
Choline bitartrate & 2.75 & 3 \\
Yellow food color & 0.1 & - \\
Blue food color & - & 0.1 \\
Total (g) & 1000 & 1000 \\
Protein (\% of kcal) & 20.1 & 18.3 \\
Carbohydrate (\% of kcal) & 69.8 & 21.4 \\
Fat (\% of kcal) & 10.2 & 60.3 \\
Energy (kcal/g) & 3.7 & 5.1 \\
\hline
\end{tabular}

2.4. Cell Viability Assay. The 3T3-L1 preadipocytes were plated at $5 \times 10^{3}$ cells/well in 96-well plates. AC extract was added to each well at various concentrations $(0,5,10,20,40$, 80,160 , and $300 \mu \mathrm{g} / \mathrm{mL}$ ) for $24,48,72$, and $96 \mathrm{~h}$. $20 \mu \mathrm{L}$ of MTS solution was added 96-well plates, after incubation 30 min, and then optical density at $490 \mathrm{~nm}$ was measured using an ELISA reader (SYNERGY H1, Microplate reader, BioTek, USA).

2.5. Animal Treatment and Experimental Protocol. Thirtytwo 5 week-old male C57BL/6N mice were purchased from Central Lab Animal (SLC, Osaka, Japan), and housed in a temperature- $\left(22 \pm 1^{\circ} \mathrm{C}\right)$ and humidity $(60 \pm 5 \%)$ controlled room with a cycle of 12-h light and 12-h of darkness for 1 week. After 1 week of rest, mice were discretionally allocated to randomly divided 4 groups $(n=8)$ as follows: fed a regular diet (RD) group; fed a high-fat diet (HFD, Research Diets, DooYeol Biotech, Seoul, Korea) group; fed a HFD plus AC $100 \mathrm{mg} / \mathrm{kg}$ (AC100) group; and fed a HFD plus AC $200 \mathrm{mg} / \mathrm{kg}$ (AC200) group (Table 1). Body weights, food and water intakes, and Blood glucose levels of all mice were recorded weekly. After 8 weeks, mice were anesthetized with diethyl ether after an overnight fast. The blood was drawn from the abdominal aorta into a vacuum tube; the epididymal fat tissues were removed, weighed, and frozen with liquid nitrogen. All the animal experimental procedures were in conformity with guidelines and with the approval of the Institutional Animal Care and Use Committees (IACUC) of Hallym University. 
TAble 2: Primer sequence.

\begin{tabular}{|c|c|c|c|}
\hline \multirow{2}{*}{ Gene } & \multicolumn{2}{|c|}{ Primer Sequence $\left(5^{\prime} \longrightarrow 3^{\prime}\right)$} & \multirow{2}{*}{$\begin{array}{l}\text { Annealing } \\
\text { temp }\left({ }^{\circ} \mathrm{C}\right)\end{array}$} \\
\hline & Forward primer & Reverse primer & \\
\hline PPAR- $\gamma$ & TTTTCAAGGGTGCCAGTTTC & AATCCTTGGCCCTCTGAGAT & 58 \\
\hline $\mathrm{C} / \mathrm{EBP} \alpha$ & AGACATCAGCGCCTACATCG & TGTAGGTGCATGGTGGTCTG & 58 \\
\hline SREBP1 & GCGCTACCGGTCTTCTATCA & TGCTGCCAAAAGACAAGGG & 58 \\
\hline FAS & GATCCTGGAACGAGAACAC & AGACTGTGGAACACGGTGGT & 50 \\
\hline SCD-1 & CGAGGGTTGGTTGTTGATCTGT & ATAGCACTGTTGGCCCTGGA & 56 \\
\hline PGC- $1 \alpha$ & CACCAAACCCACAGAAAACAG & GGGTCAGAGGAAGAGATAAAGTTG & 60 \\
\hline PPAR $\alpha$ & ATGAAGAGGGCTGAGCGTAGGTAA & TGCCGTTGTCTGTCACTGTCTGAA & 57 \\
\hline ATGL & ACCAACACCAGCATCCAGTT & TTTGCACATCTCTCGGAGGA & 56 \\
\hline HSL & TTCGAGGGTGATGAAGGACT & ACTCTGGGTCTATGGCGAAT & 58 \\
\hline Actin & GTCGTACCACTGGCATTGTG & GCCATCTCCTGCTCAAAGTC & 60 \\
\hline
\end{tabular}

2.6. Serum Chemistry Analysis. The plasma concentrations of glucose, triglyceride (TG), total cholesterol (TC), and lowdensity lipoprotein (LDL) cholesterol levels were determined using commercial kits (Thermo Electron Corporation, Vantaa, Finland) and a Thermo Fisher Konelab 20XTi Analyzer (Thermo Electron Corporation, SeoKwang LABOTECH, Seoul, Korea).

2.7. Hematoxylin and Eosin Staining. The epididymal adipose tissues were removed and fixed in $10 \%$ fresh formalin solution for $24 \mathrm{~h}$. The each group tissue sample was embedded in paraffin wax, sectioned in $5 \mu \mathrm{m}$ thicknesses, and stained with hematoxylin and eosin ( $\mathrm{H} \& \mathrm{E})$ for microscopic assessment (Axiomager, Zeiss, Germany).

2.8. RT-PCR and Real-Time PCR. The total RNA was isolated from the 3T3-L1 adipocytes and epididymal adipose tissue using a Trizol (Invitrogen, Carlshad, CA, USA), and quantified with a NanoDrop-2000 (Thermo Fisher Scientific, Wilmington, DE, USA). The cDNA was generated from 5 $\mu \mathrm{g}$ of total RNA using a Reverse Transcription System kit (Promega, Fitchburg, WI, USA). PCR was performed at $95^{\circ} \mathrm{C}$ for $30 \mathrm{~s}$ followed by annealing for $30 \mathrm{~s}$ and then at $72^{\circ} \mathrm{C}$ for 1 min. The last cycle was followed by a final extension step at $72^{\circ} \mathrm{C}$ for $10 \mathrm{~min}$. The RT-PCR products were electrophoresed in $0.8 \%$ agarose gel under $100 \mathrm{~V}$ and were stained with 0.5 $\mu \mathrm{g} / \mathrm{mL}$ ethidium bromide. Levels of the reference gene Actin were used to correct for differences in RNA isolation, RNA degradation, and the efficiency of the reverse transcription. Real-time PCR was performed using $1 \mu \mathrm{L}$ of cDNA in a $20 \mu \mathrm{L}$ reaction volume with the ABI PRISM 7000 sequence detector system (Applied Biosystems, Foster City, CA, USA). The temperature profile of the reaction was $95^{\circ} \mathrm{C}$ for 15 min, followed by 30 cycles of denaturation at $95^{\circ} \mathrm{C}$ for $30 \mathrm{~s}$, and extension at $72^{\circ} \mathrm{C}$ for $1 \mathrm{~min}$. A relative gene expression quantification method was used to calculate the fold change of mRNA expression according to the comparative threshold cycle method using actin as an endogenous control. Primer sequences are shown in Table 2 .

2.9. Western Blot Analysis. To detect proteins from whole adipocyte cell lysates, 3T3-L1 cells and epididymal adipose tissue were homogenized in lysis buffer. The protein concentration of the cell lysates was measured using a Bio-Rad protein assay kit (Hercules, CA). The primary antibodies PPAR $\gamma$, C/EBP $\alpha$, SREBP1, FAS, SCD-1, phosphor-AMPK (pAMPK), AMPK, phosphor-ACC (p-ACC), ACC, PGC-1 $\alpha$, PPAR $\alpha$, ATGL, phosphor-hormone sensitive lipase (p-HSL), and HSL were purchased form Cell Signaling (Danver, USA).

2.10. Statistical Analysis. The results are presented as the mean \pm SEM, and data were compared using a Student's unpaired $t$-test or one-way analysis of variance (ANOVA), as appropriate. Differences of $p<0.05,0.01$, and 0.001 were considered statistically significant.

\section{Results}

3.1. Chemical Composition of AC Extract. Phytochemical screening of AC extract showed positive results for flavonoids, steroids, and triterpenoids using HPTLC (data not shown). As shown in Figure 1, the major constituents with moderate and high polarity during $0-12$ min retention time. The observed triterpenoids were assigned Astilbic acid (3 $\beta, 6 \beta$-dihydroxyolean-12-en-27-oic acid) by comparing the retention times with the isolated compounds in HPLC chromatograms and analysis of MS data. The AC extract contained $96.3 \pm 0.8 \mathrm{mg} / \mathrm{g}$ astilbic acid.

3.2. Effect of AC Extract on Adipocyte Differentiation. We first performed an MTS assay to assess the effect of AC extract on 3T3-L1 cell viability. As shown in Figure 1(a), the treatment of $5,10,20,40,80,160$, and $300 \mu \mathrm{g} / \mathrm{mL}$ of AC extract for $24,48,72$, and $96 \mathrm{~h}$ resulted in no significant effects on cell viability. Next, to elucidate the effect of AC extract on the differentiation of preadipocytes into adipocytes, 3T3-L1 cells were treated with the indicated concentrations of AC extract and lipid accumulation was examined by using Oil Red O staining. As shown in Figure 2(b), AC extract reduced lipid droplet size compared with cells grown in differentiated media. Differentiation of 3T3-L1 adipocytes was inhibited by treatment with AC extract, and triglyceride content in 3T3L1 adipocytes significantly decreased in AC extract-treated cells at 20 and $40 \mu \mathrm{g} / \mathrm{mL}$. RT-PCR and western blotting 


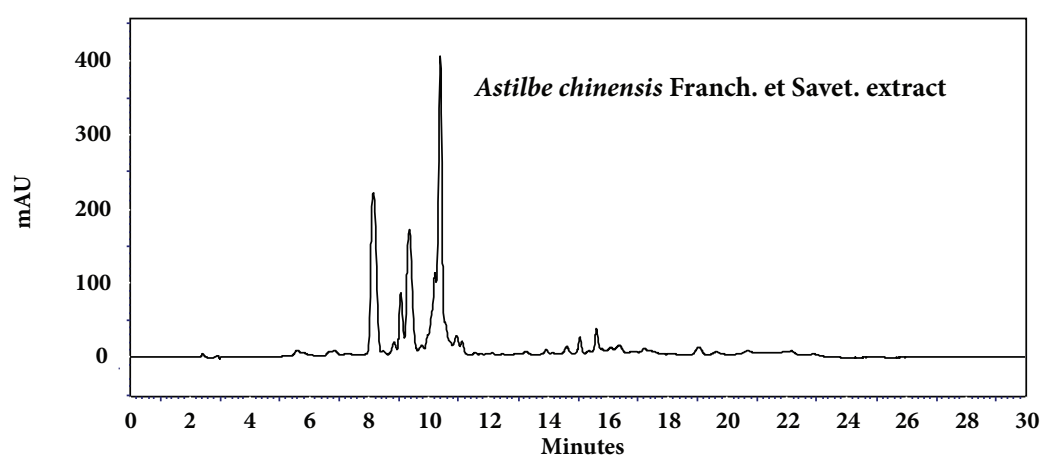

(a)

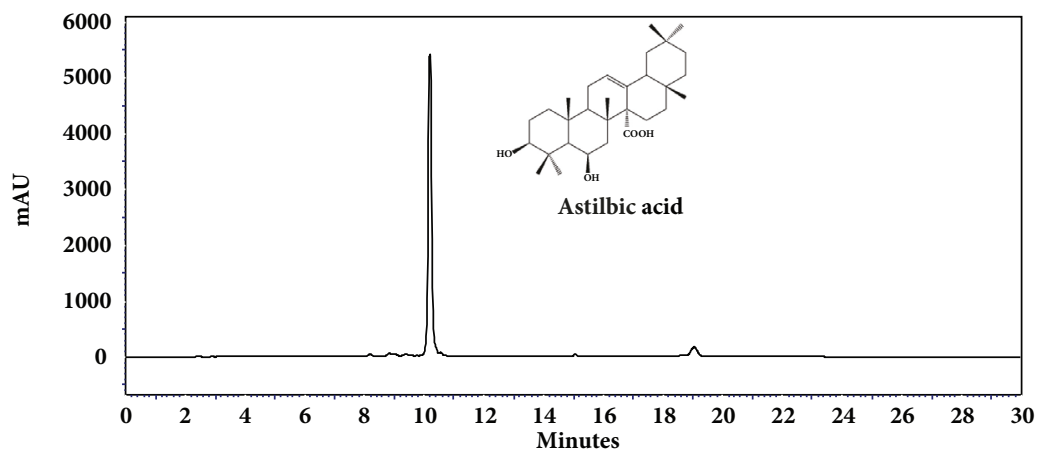

(b)

FIgURE 1: HPLC Chromatograms of Astilbe chinenesis Franch. et Savet. extract (a) and the standard astilbic acid (b).

analyses were used to quantify the expression of adipogenesis markers, such as peroxisome proliferator-activated receptor$\gamma(\mathrm{PPAR}-\gamma)$, CCAAT/enhancer binding protein $\alpha(\mathrm{C} / \mathrm{EBP} \alpha)$, and sterol regulatory element-binding protein-1 (SREBP-1) in 3T3-L1 adipocytes. However, AC extract caused significant downregulation of the expression of PPAR $-\gamma, \mathrm{C} / \mathrm{EBP} \alpha$, and SREBP1 and its target molecules, fatty acid synthase (FAS), and stearoyl-CoA desaturase-1 (SCD-1), in comparison with differentiated cells.

3.3. Activation of AMPK Pathway by AC Extract in 3T3-L1 Adipocytes. AMPK is an important cellular energy metabolism sensor with a key role in the regulation of adipogenesis and lipolysis [11, 12]. We next examined whether AC extract stimulated the phosphorylation of AMPK in 3T3L1 adipocytes. As shown in Figure 3(a), treatment with AC extract resulted in a significant dose-dependent activation of AMPK and ACC. Furthermore, the protein and mRNA expression of PGC- $1 \alpha, \operatorname{PPAR} \alpha$, ATGL, and HSL, which are critical regulators of mitochondrial biogenesis and lipolysis, were significantly increased by AC extract treatment at 40 $\mathrm{mg} / \mathrm{mL}$ (Figures 3(b) and 3(c)). These data indicated that AC extract treatment inhibited adipogenesis and increased lipolysis mediated by AMPK activation.

3.4. Effects of AC Extract on Body Weight and Biomarkers in High-Fat Diet Induced Obese Mice. To assess whether AC extract caused an anti-adipogenic and lipolytic effect in vivo, we used an HFD-induced obese model. The effects of 100 and $200 \mathrm{mg} / \mathrm{kg}$ AC extract on body weight and metabolic parameters in high-fat-diet-induced obese mice treated for 8 weeks are shown in Table 3. There was no significant difference in the initial body weight and the food intake between the RD and HFD groups. However, the body weight gains in AC extract-treated mice were significantly smaller than those in the HFD group, after 8 weeks on the experimental diet (55\% decrease in the AC100 group and $61 \%$ decrease in the AC200 group). At the end of the treatment period, the changes in plasma glucose, insulin, and lipid levels were also examined. The plasma glucose and insulin levels were higher in the HFD group than in the RD group, but AC extract treatment significantly reduced the plasma glucose and insulin levels in a concentration-dependent manner. The AC100 and AC200 groups showed a significant decrease in the levels of TG, TC, and LDL-cholesterol (22\%, $56 \%$, and $40 \%$ inhibition in the AC200 group, respectively).

3.5. Effects of AC Extract on Epididymal Adipose Tissue. To elucidate the weight-reducing effect of AC extract in HFDinduced obese mice, the volume of adipose tissues was measured by using $\mathrm{H} \& \mathrm{E}$ staining. The epididymal adipocyte size was significantly larger in the HFD group than in the $\mathrm{RD}$ group, whereas the adipocyte size was smaller in the AC extract-treated group than the untreated HFD-induced obese mice (Figures 4(a) and 4(b)). To evaluate the AC extractinduced reduction in adipocyte size, we measured the gene and protein expression in the epididymal adipose tissue of 


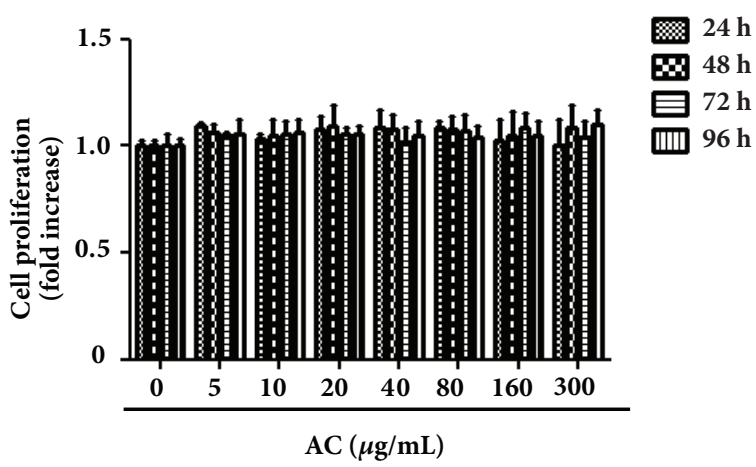

(a)
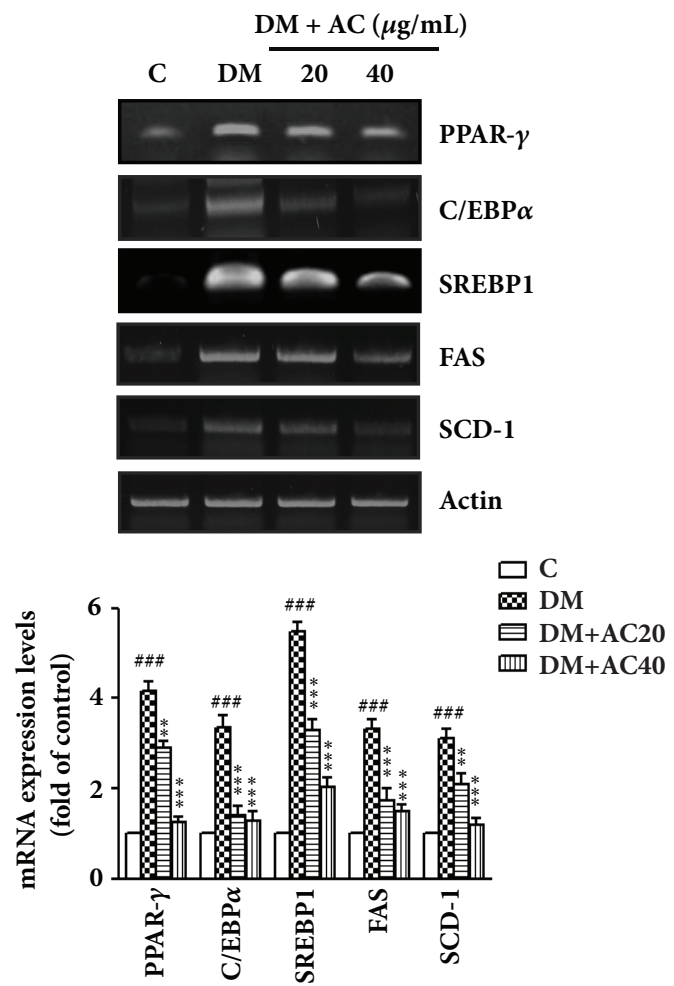

(c)

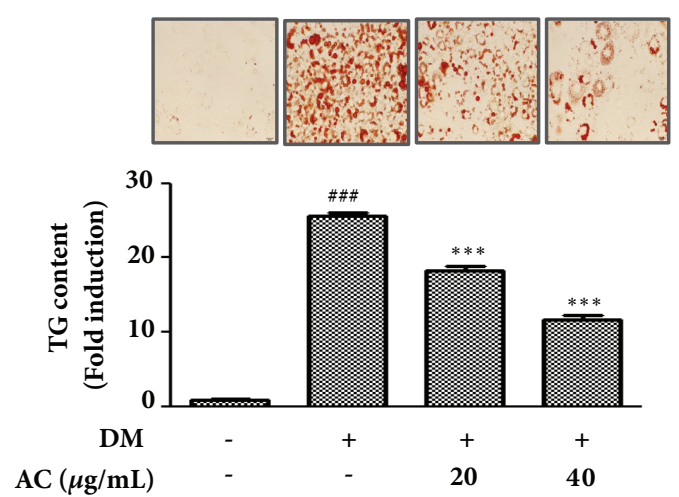

(b)
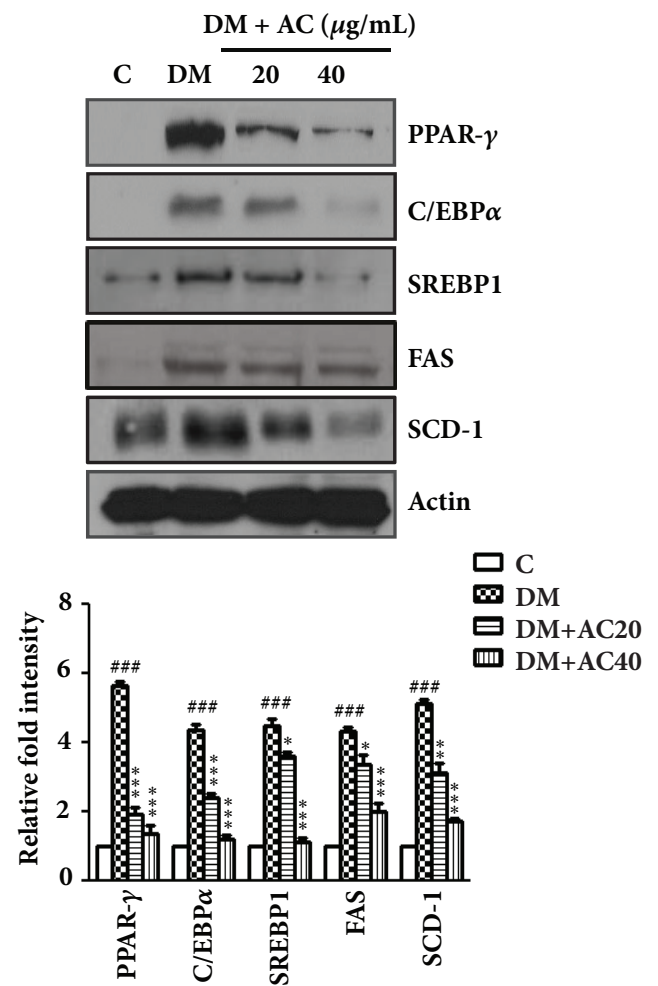

(d)

FIgure 2: Effects of the Astilbe chinensis Franch. et Savat. (AC) extract on inhibiting 3T3-L1 adipocyte differentiation. (a) The 3T3-L1 cell proliferation was measured by MTS assay after $24 \mathrm{~h}, 48 \mathrm{~h}, 72 \mathrm{~h}$, and $96 \mathrm{~h}$ treatment of AC extract at various concentrations. (b) The 3T3-L1 cells differentiated with differentiation medium in the absence or presence of AC extract for 8 days. Intracellular lipids were stained with Oil Red $\mathrm{O}$, and triglyceride content was quantified by spectrometry at $540 \mathrm{~nm}$. (c) mRNA levels of PPAR- $\gamma, \mathrm{C} / \mathrm{EBP} \alpha$, SREBP1, FAS, and SCD-1, as determined by reverse transcription PCR (upper panels) and real-time PCR (lower panels), and (d) the protein expression levels of PPAR- $\gamma$, C/EBP $\alpha$, SREBP1, FAS, and SCD-1 were examined by western blot analyses. Data are presented as the mean \pm SEM of three independent experiments, each performed in triplicate. ${ }^{\# \#} p<0.001 v s$ untreated cells; ${ }^{*} p<0.05,{ }^{* *} p<0.01$ and ${ }^{* * *} p<0.001 v s$ differentiated cells (DM).

HFD-induced obese mice. The gene expression of PPAR$\gamma, \mathrm{C} / \mathrm{EBP} \alpha$, SREBP1, FAS, and SCD-1 was dose-dependently reduced in AC extract-treated mice compared with HFD mice (Figures 4(c) and 4(d)).

3.6. AC Extract Regulated Gene Expression of Lipid Metabolism in Epididymal Fat Tissue. The current literature indicates that adipose triglyceride lipase (ATGL) and hormonesensitive lipase (HSL) are the major lipases for approximately $95 \%$ of lipase activity in white adipose tissue [13]. Thus, we examined the effects of AC extract on the AMPK pathways in epididymal fat tissue. In contrast, pAMPK, pACC, PGC$1 \alpha$, PPAR- $\alpha$, ATGL, and HSL were markedly induced in AC extract-treated mice, as shown in Figure 5.

\section{Discussion}

Obesity is considered a major cause of several metabolic diseases, including type 2 diabetes mellitus, hypertension, dyslipidemia, and cardiovascular disease $[14,15]$. Although 


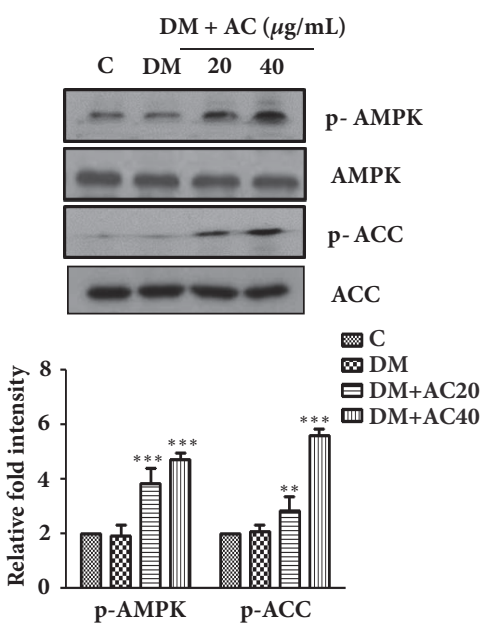

(a)
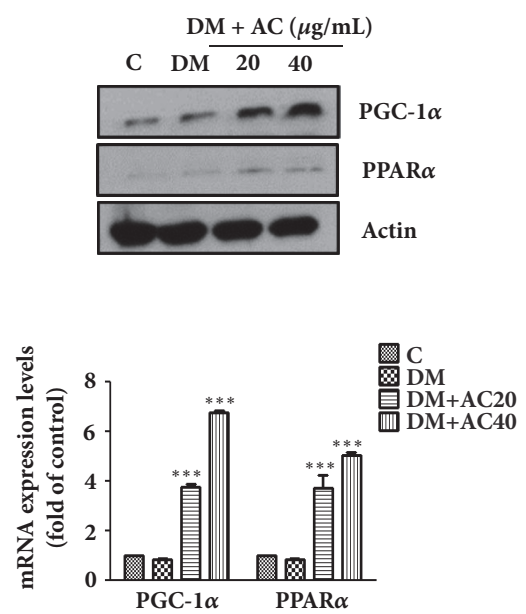

(b)
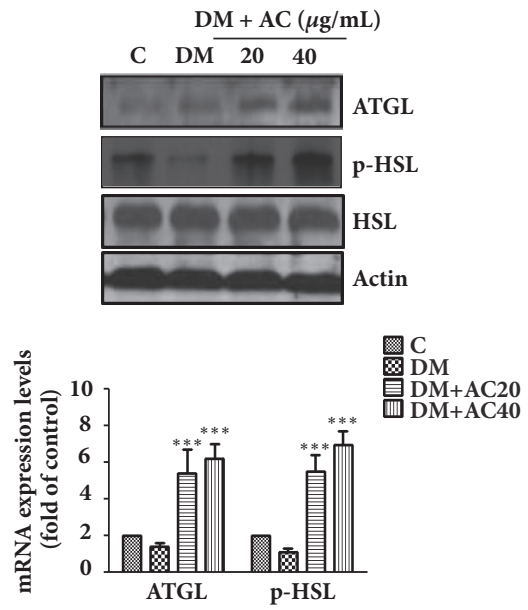

(c)

Figure 3: The effect of Astilbe chinensis Franch. et Savat. (AC) extract on gene expression in 3T3-L1 adipocytes. (a) Expression of AMPK, ACC phosphorylation, (b) PGC-1 $\alpha$, PPAR $\alpha$ and (c) ATGL, p-HSL mRNA and protein activated in the 3T3-L1 adipocytes and normalized by western blot (upper) and real-time PCR (lower). Data are presented as the mean \pm SEM of three independent experiments, each performed in triplicate. ${ }^{*} p<0.05,{ }^{* *} p<0.01$, and ${ }^{* * *} p<0.001$ compared with differentiated cells (DM).

TABle 3: Effects of Astilbe chinensis Franch.et Savat. extract on body weight and biomarkers in mice fed a high-fat diet.

\begin{tabular}{|c|c|c|c|c|}
\hline Groups & RD & HFD & AC 100 & AC 200 \\
\hline Initial body weight (g) & $21.2 \pm 1.5^{\mathrm{NS}}$ & $21.7 \pm 1.2^{\mathrm{NS}}$ & $21.8 \pm 1.3^{\mathrm{NS}}$ & $21.7 \pm 1.4^{\mathrm{NS}}$ \\
\hline Final body weight (g) & $29.8 \pm 2.3^{\mathrm{a}}$ & $43.5 \pm 2.4^{c}$ & $31.8 \pm 1.9^{\mathrm{ab}}$ & $30.2 \pm 2.3^{\mathrm{ab}}$ \\
\hline Body weight gain (g) & $8.5 \pm 1.9^{\mathrm{a}}$ & $21.6 \pm 1.5^{\mathrm{c}}$ & $9.8 \pm 1.3^{\mathrm{ab}}$ & $8.4 \pm 1.6^{\mathrm{ab}}$ \\
\hline Food intake (g/day) & $3.13 \pm 0.2^{\mathrm{NS}}$ & $3.26 \pm 0.3^{\mathrm{NS}}$ & $3.31 \pm 0.2^{\mathrm{NS}}$ & $3.28 \pm 0.2^{\mathrm{NS}}$ \\
\hline Feed efficiency & $0.72 \pm 0.1^{\mathrm{a}}$ & $3.66 \pm 0.2^{\mathrm{c}}$ & $1.79 \pm 0.1^{\mathrm{b}}$ & $1.33 \pm 0.2^{\mathrm{ab}}$ \\
\hline Plasma glucose (mM) & $5.3 \pm 0.7^{\mathrm{a}}$ & $8.6 \pm 0.8^{c}$ & $6.1 \pm 1.3^{\mathrm{b}}$ & $6.0 \pm 0.4^{\mathrm{b}}$ \\
\hline Plasma insulin $(\mu \mathrm{U} / \mathrm{mL})$ & $60.1 \pm 6.8^{\mathrm{a}}$ & $163.6 \pm 13.7^{\mathrm{C}}$ & $87.3 \pm 7.7^{\mathrm{b}}$ & $74.3 \pm 11.3^{\mathrm{ab}}$ \\
\hline $\mathrm{TG}(\mathrm{mg} / \mathrm{mL})$ & $48.7 \pm 6.9^{\mathrm{a}}$ & $88.3 \pm 9.9^{c}$ & $42.3 \pm 7.0^{\mathrm{a}}$ & $68.5 \pm 22.6^{\mathrm{b}}$ \\
\hline $\mathrm{TC}(\mathrm{mg} / \mathrm{mL})$ & $50.8 \pm 4.0^{\mathrm{a}}$ & $116.1 \pm 5.6^{\mathrm{b}}$ & $58.4 \pm 6.5^{\mathrm{a}}$ & $51.1 \pm 11.2^{\mathrm{a}}$ \\
\hline LDL-cholesterol (mg/mL) & $13.3 \pm 2.3^{\mathrm{a}}$ & $32.3 \pm 3.2^{c}$ & $21.1 \pm 1.8^{\mathrm{b}}$ & $19.3 \pm 2.1^{\mathrm{b}}$ \\
\hline
\end{tabular}

Results are presented as mean \pm SEM $(n=8)$. Values within a row with different letters are significantly different from each other $(p<0.05)$. RD: regular diet group; HFD, high-fat diet group; AC 100, HFD + Astilbe chinensis Franch. et Savat. (AC) extract $100 \mathrm{mg} / \mathrm{kg}$ treatment; AC 200, HFD + Astilbe chinensis Franch. et Savat. (AC) extract $200 \mathrm{mg} / \mathrm{kg}$ treatment; TG: triacylglycerol; TC: total cholesterol; LDL: low-density lipoprotein; ${ }^{\text {NS }}$ : not significant.

many scientists are actively developing therapies for obesity, natural products suitable for the treatment of obesity have been frequently suggested as an alternative strategy owing to the severe adverse effects induced by antiobesity drugs [16]. In this study, we investigated the antidifferentiation effect of AC extract on 3T3-L1 preadipocytes and explored the antiobesity activity of AC extract in HFD-induced obese C57BL/6N mice.

It is well known that adipogenesis is a differentiation process associated with the expansion of adipose tissue and induces obesity $[17,18]$. During adipocyte differentiation, adipocyte markers, such as PPAR- $\gamma, \mathrm{C} / \mathrm{EBP} \alpha$, and SREBP1, are considered key regulators of adipogenesis $[19,20]$. In the present study, AC extract significantly decreased the mRNA and protein expression of the adipogenic transcription factor genes PPAR- $\gamma, \mathrm{C} / \mathrm{EBP} \alpha$, and SREBP1 (Figure 2) and its target molecules FAS and SCD-1 in differentiated 3T3-L1 cells and the epididymal fat tissue of HFD-induced obese mice. These results suggest that $\mathrm{AC}$ extracts may prevent weight gain in HFD-induced obese C57BL/6N mice.

Recent evidence has shown that basic cellular metabolic pathways play a major role in the regulation of wholebody energy homeostasis [21]. Among them, a master sensor and regulator of energy homeostasis, the AMPK pathway, has been examined at the cellular level [22-24]. AMPK activates the catabolic processes that provide alternative routes for ATP generation, glucose uptake, glycolysis, fatty acid oxidation, and mitochondrial biogenesis. The PPAR- $\gamma$ coactivator- $1 \alpha$ (PGC- $1 \alpha$ ) and PPAR- $\alpha$ are critical regulators of mitochondrial biogenesis and energy expenditure induced by AMPK activation $[25,26]$. However, as shown in Figures 3 and 5, AC extract stimulated the phosphorylation of AMPK, PGC- $1 \alpha$, and PPAR- $\alpha$ in a dose-dependent manner. These results indicated that $\mathrm{AC}$ extracts induced the activation of 


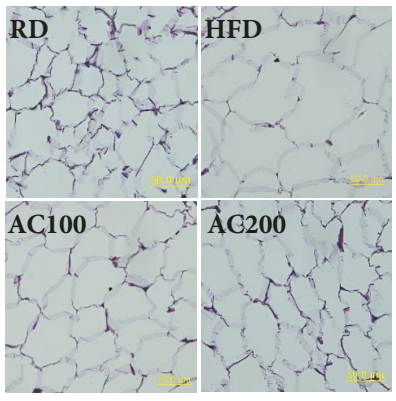

(a)
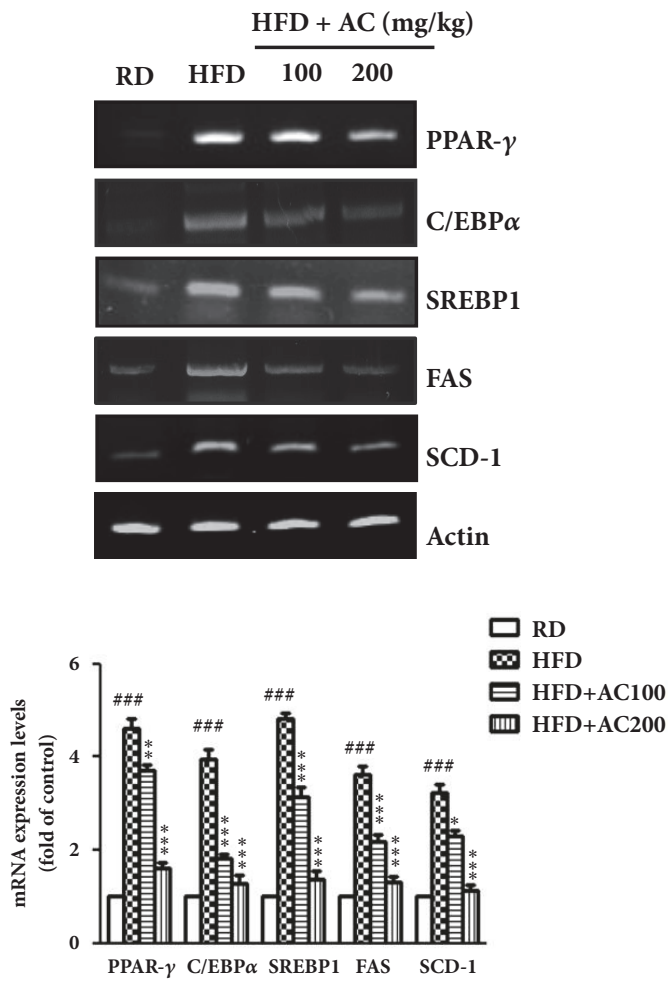

(c)
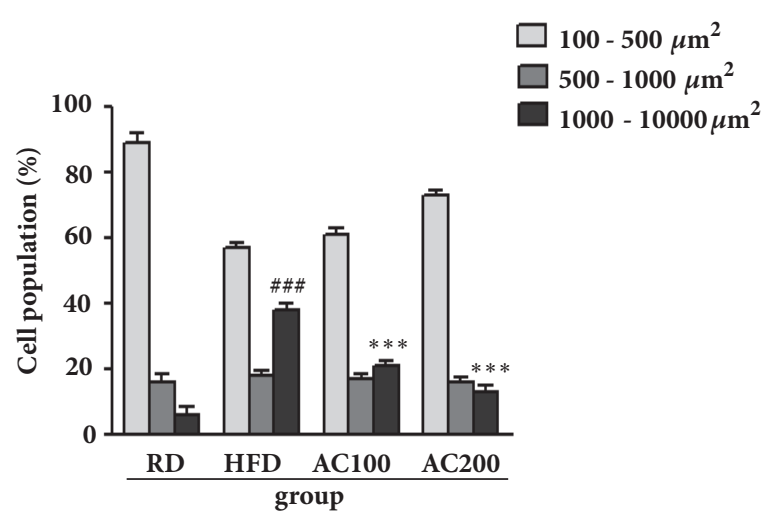

(b)
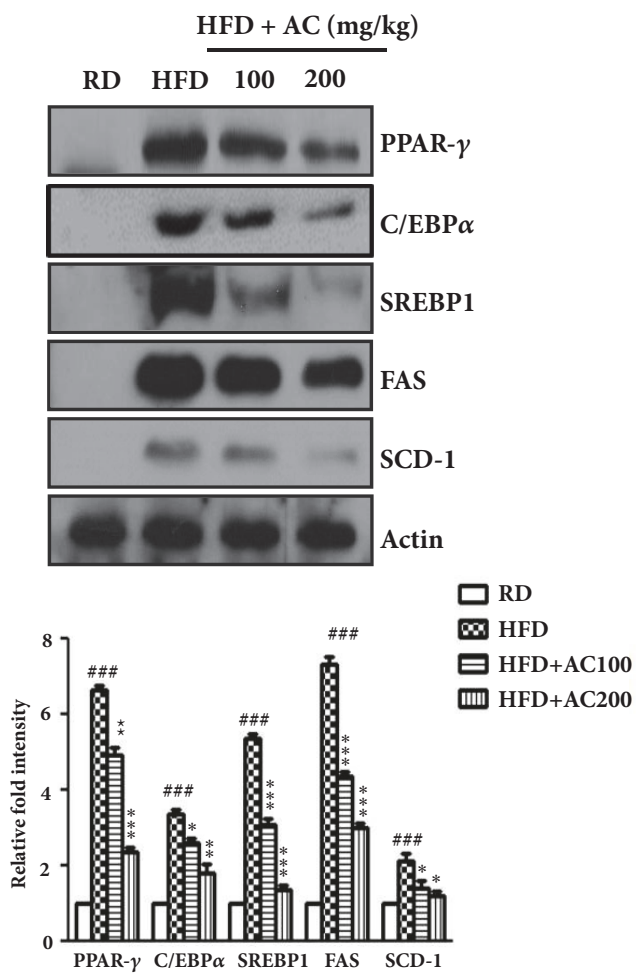

(d)

Figure 4: Effects of Astilbe chinensis Franch. et Savat. (AC) extract on epididymal fat size in HFD induced obese mice. (a) The H \& E stained epididymal fat tissue from HFD induced obese mice treated with RD or AC (100 and $200 \mathrm{mg} / \mathrm{kg}$ ), and (b) quantification of epididymal fat tissues size were calculated. The (c) mRNA levels of PPAR- $\gamma$, C/EBP $\alpha$, SREBP1, FAS, and SCD-1, as determined by reverse transcription PCR (upper panels) and real-time PCR (lower panels), and (d) the protein levels of PPAR- $\gamma$, C/EBP $\alpha$, SREBP1, FAS, and SCD- 1 were examined by western blot analyses, respectively. ${ }^{\# \#} p<0.001 v \mathrm{RD}$ mice; ${ }^{*} p<0.05,{ }^{* *} p<0.01$, and ${ }^{* * *} p<0.001$ compared with HFD mice.

the AMPK-mediated gene expression increase in PGC- $1 \alpha$ and PPAR $\alpha$, which drove lipid metabolism toward energy dissipation instead of storage.

ATGL and HSL are major regulators of lipolysis in the white adipose tissue of rodents [27, 28]. It is well known that ATGL initiates lipolysis through the cleavage of the first fatty acids (FAs) from triacylglycerols (TAGs), which is followed by the action of HSL and MAGL on diacylglycerols (DAGs) and monoacylglycerols. However, recent research has shown that AMPK, via a cAMP-dependent mechanism, is required for the activation of lipolysis in 3T3-L1 adipocytes [29] and stimulates lipolysis in 3T3-L1 adipocytes through the phosphorylation of HSL [30]. Thus, the orchestrated activation of AMPK, ATGL, and HSL appears to be a requirement for the occurrence of complete lipolysis in adipocytes. In the present study, AC extract was found to stimulate lipolysis in HFD-induced obese mice and 3T3-L1 adipocytes through a direct increase in the expression of ATGL and the phosphorylation of HSL, AMPK, and ACC (Figure 6). 


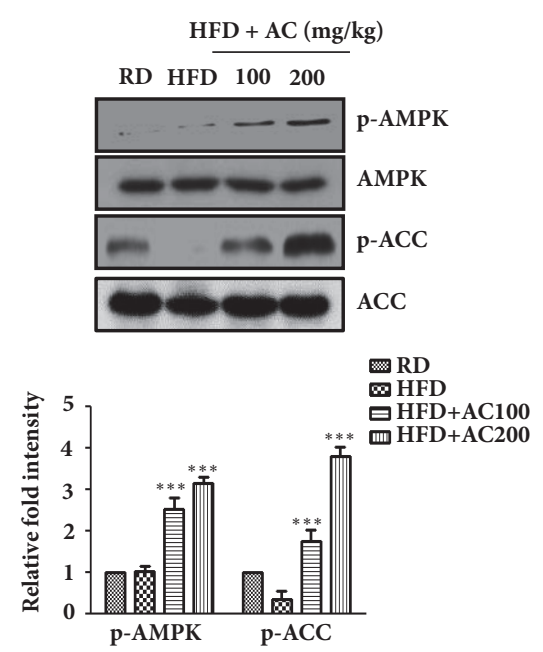

(a)

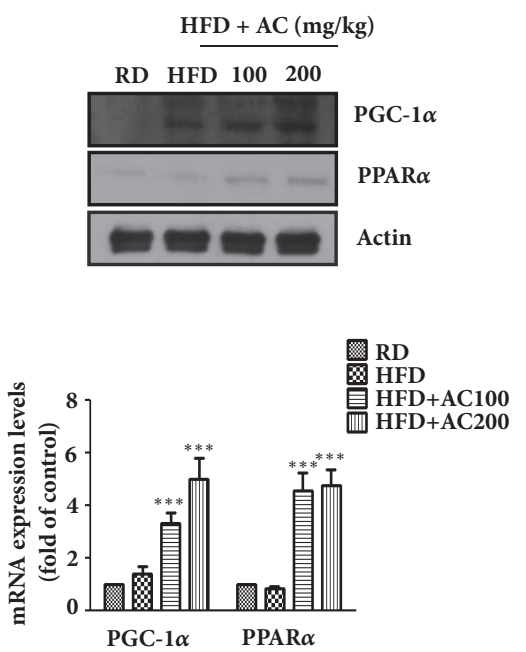

(b)

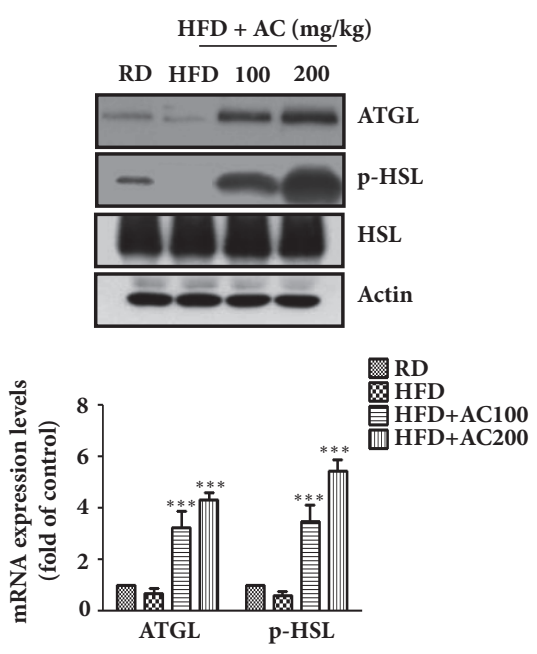

(c)

FIgURE 5: Effects of Astilbe chinensis Franch. et Savat. (AC) extract on AMPK and ACC phosphorylation (a), PGC-1 $\alpha$, PPAR $\alpha$ (b) and ATGL, p-HSL (c) gene expression in the epididymal fat, and determined by western blot (upper) and real-time PCR (lower). ${ }^{* * *} p<0.001$ compared with HFD mice.

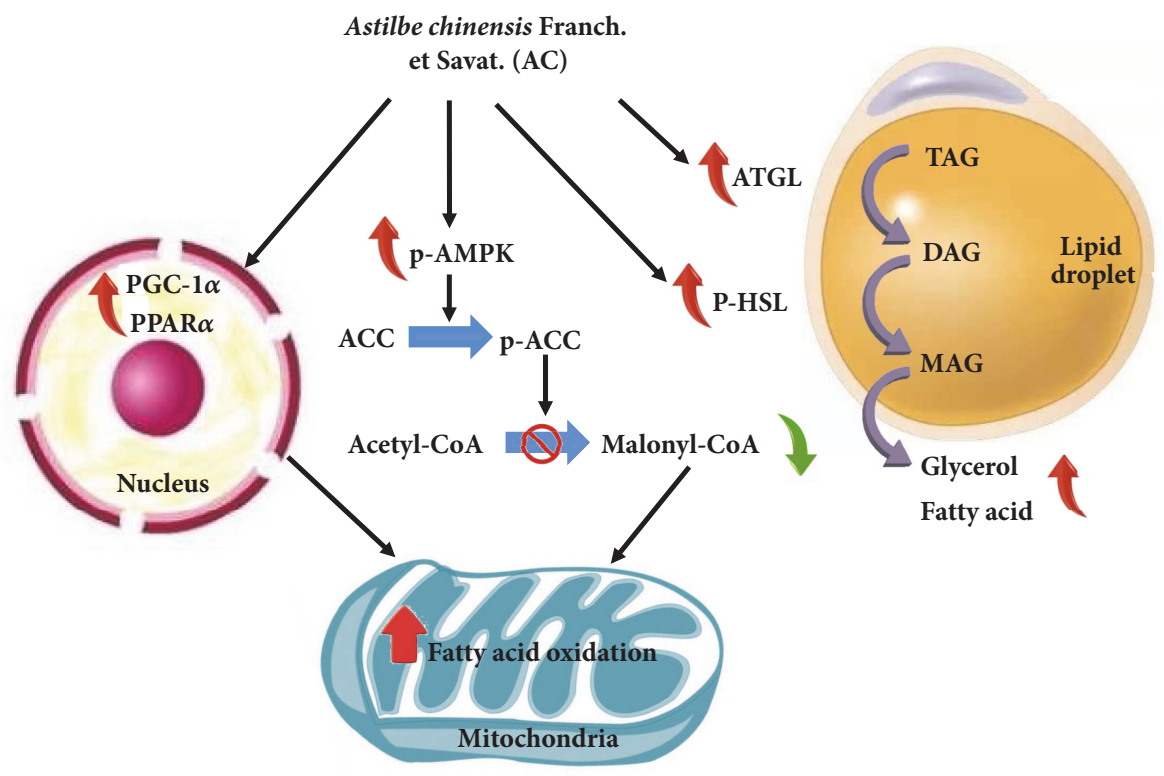

Figure 6: Proposed antiobesity mechanisms of Astilbechinensis Franch. et Savat.

In conclusion, we demonstrated that supplementation with AC extract significantly suppressed adipocyte differentiation in 3T3-L1 cells, as well as body weight gain, feed efficiency levels, adipose tissue size, and the serum levels of glucose, insulin, TG, and TC in HFD-induced obese C57BL/6N mice. Furthermore, AC extract altered the expression of many genes that are related to adipocyte differentiation and lipolysis. In summary, these results have provided molecularlevel information to permit further investigation of the mechanisms through which AC extract moderated lipid metabolism. Further investigations are required to identify the responsible compounds in AC and their mechanisms of action.

\section{Data Availability}

The data used to support the findings of this study are available from the corresponding author upon request.

\section{Conflicts of Interest}

The authors declare no conflicts of interest. 


\section{Authors' Contributions}

Bo Huang and Soon Sung Lim designed the experiments. Xian Hua Zhang, Zhiqiang Wang, Bueom-Goo Kang, Seung Hwan Hwang, and Jae-Young Lee performed the experiments. Xian Hua Zhang, Bo Huang, and Jae-Young Lee analyzed the data.

\section{Acknowledgments}

This research was supported by the Basic Science Research Program through the National Research Foundation of Korea (NRF) funded by the Ministry of Education (2015R1D1A1A01059199) and the Natural Science Foundation of Liaoning Province (Grant nos. 201602285, 201602334). The authors are grateful to Soo Kyeong Lee for helpful experiments in this study.

\section{References}

[1] M. Periasamy, J. L. Herrera, and F. C. G. Reis, "Skeletal muscle thermogenesis and its role in whole body energy metabolism," Diabetes \& Metabolism, vol. 41, no. 5, pp. 327-336, 2017.

[2] C. Jiang, M. Zhai, D. Yan et al., "Dietary menthol-induced TRPM8 activation enhances WAT 1C "browning 1D" and ameliorates diet-induced obesity," Oncotarget, vol. 8, no. 43, pp. 75114-75126, 2017.

[3] B. M. Spiegelman and J. S. Flier, "Obesity and the regulation of energy balance," Cell, vol. 104, no. 4, pp. 531-543, 2001.

[4] N. E. Lepor, D. D. Fouchia, and P. A. McCullough, "New vistas for the treatment of obesity: Turning the tide against the leading cause of morbidity and cardiovascular mortality in the developed world," Reviews in Cardiovascular Medicine, vol. 14, no. 1, pp. 21-40, 2013.

[5] S. V. Joyal, "A perspective on the current strategies for the treatment of obesity," CNS \& Neurological Disorders - Drug Targets, vol. 3, no. 5, pp. 341-356, 2004.

[6] A. J. Krentz, K. Fujioka, and M. Hompesch, "Evolution of pharmacological obesity treatments: focus on adverse side-effect profiles," Diabetes, Obesity and Metabolism, vol. 18, no. 6, pp. 558-570, 2016.

[7] Y. Xue, X. Xu, J. Yan, W. Deng, and X. Liao, “ Chemical constituents from ," Journal of Asian Natural Products Research, vol. 13, no. 2, pp. 188-191, 2011.

[8] H.-X. Sun, Y.-P. Ye, and Y.-J. Pan, "Cytotoxic oleanane triterpenoids from the rhizomes of Astilbe chinensis (Maxim.) Franch. et Savat.," Journal of Ethnopharmacology, vol. 90, no. 23, pp. 261-265, 2004.

[9] T. C. Moon, C. X. Lin, J. S. Lee, D. S. Kim, K. Bae, and K. H. Son, "Antiinflammatory activity of astilbic acid from Astilbe chinensis," Biological \& Pharmaceutical Bulletin, vol. 28, no. 1, pp. 24-26, 2005.

[10] Y.-B. Zhang, X.-Y. Peng, and H.-X. Sun, "A new cytotoxic, apoptosis-inducing triterpenoid from the rhizomes of Astilbe chinensis," Chemistry \& Biodiversity, vol. 5, no. 1, pp. 189-196, 2008.

[11] B. Huang, H. D. Yuan, D. Y. Kim, H. Y. Quan, and S. H. Chung, "Cinnamaldehyde prevents adipocyte differentiation and adipogenesis via regulation of peroxisome proliferatoractivated receptor- $\gamma(\operatorname{PPAR} \gamma)$ and AMP-activated protein kinase (AMPK) pathways," Journal of Agricultural and Food Chemistry, vol. 59, no. 8, pp. 3666-3673, 2011.

[12] H.-J. Koh, M. F. Hirshman, H. He et al., "Adrenaline is a critical mediator of acute exercise-induced AMP-activated protein kinase activation in adipocytes," Biochemical Journal, vol. 403, no. 3, pp. 473-481, 2007.

[13] M. Schweiger, R. Schreiber, G. Haemmerle et al., "Adipose triglyceride lipase and hormone-sensitive lipase are the major enzymes in adipose tissue triacylglycerol catabolism," The Journal of Biological Chemistry, vol. 281, no. 52, pp. 40236-40241, 2006.

[14] M. S. Bray, "Genomics, genes, and environmental interaction: The role of exercise," Journal of Applied Physiology, vol. 88, no. 2, pp. 788-792, 2000.

[15] I. Torre-Villalvazo, L. G. Cervantes-Pérez, L. G. Noriega et al., "Inactivation of SPAK kinase reduces body weight gain in mice fed a high-fat diet by improving energy expenditure and insulin sensitivity," American Journal of Physiology-Endocrinology and Metabolism, vol. 314, no. 1, pp. E53-E65, 2018.

[16] J. W. Yun, "Possible anti-obesity therapeutics from nature-a review," Phytochemistry, vol. 71, no. 14-15, pp. 1625-1641, 2010.

[17] G. Frühbeck, J. Gómez-Ambrosi, F. J. Muruzábal, and M. A. Burrell, "The adipocyte: a model for integration of endocrine and metabolic signaling in energy metabolism regulation," American Journal of Physiology-Endocrinology and Metabolism, vol. 280, no. 6, pp. E827-E847, 2001.

[18] J. M. Ntambi and K. Young-Cheul, "Adipocyte Differentiation and Gene Expression," Journal of Nutrition, vol. 130, no. 12, pp. 3122S-3126S, 2000.

[19] G. J. Darlington, S. E. Ross, and O. A. MacDougald, "The role of C/EBP genes in adipocyte differentiation," The Journal of Biological Chemistry, vol. 273, no. 46, pp. 30057-30060, 1998.

[20] R. F. Morrison and S. R. Farmer, "Hormonal signaling and transcriptional control of adipocyte differentiation," Journal of Nutrition, vol. 130, no. 12, pp. 3116S-3121S, 2000.

[21] R. Lage, C. Diéguez, A. Vidal-Puig, and M. López, "AMPK: a metabolic gauge regulating whole-body energy homeostasis," Trends in Molecular Medicine, vol. 14, no. 12, pp. 539-549, 2008.

[22] D. Carling, "The AMP-activated protein kinase cascade-a unifying system for energy control," Trends in Biochemical Sciences, vol. 29, no. 1, pp. 18-24, 2004.

[23] B. B. Kahn, T. Alquier, D. Carling, and D. G. Hardie, "AMPactivated protein kinase: ancient energy gauge provides clues to modern understanding of metabolism," Cell Metabolism, vol. 1, no. 1, pp. 15-25, 2005.

[24] D. G. Hardie, "AMP-activated/SNF1 protein kinases: conserved guardians of cellular energy," Nature Reviews Molecular Cell Biology, vol. 8, no. 10, pp. 774-785, 2007.

[25] P. Puigserver, Z. Wu, C. W. Park, R. Graves, M. Wright, and B. M. Spiegelman, "A cold-inducible coactivator of nuclear receptors linked to adaptive thermogenesis," Cell, vol. 92, no. 6, pp. 829$839,1998$.

[26] M. P. Gaidhu, S. Fediuc, N. M. Anthony et al., "Prolonged AICAR-induced AMP-kinase activation promotes energy dissipation in white adipocytes: novel mechanisms integrating HSL and ATGL," Journal of Lipid Research, vol. 50, no. 4, pp. 704-715, 2009.

[27] P. Arner, "Human fat cell lipolysis: biochemistry, regulation and clinical role," Best Practice \& Research Clinical Endocrinology \& Metabolism, vol. 19, no. 4, pp. 471-482, 2005. 
[28] M. Lafontan and D. Langin, "Lipolysis and lipid mobilization in human adipose tissue," Progress in Lipid Research, vol. 48, no. 5, pp. 275-297, 2009.

[29] W. Yin, J. Mu, and M. J. Birnbaum, "Role of AMP-activated Protein Kinase in Cyclic AMP-dependent Lipolysis in 3T3-L1 Adipocytes," The Journal of Biological Chemistry, vol. 278, no. 44, pp. 43074-43080, 2003.

[30] A. J. Smith, B. R. Thompson, M. A. Sanders, and D. A. Bernlohr, "Interaction of the adipocyte fatty acid-binding protein with the hormone-sensitive lipase: Regulation by fatty acids and phosphorylation," The Journal of Biological Chemistry, vol. 282, no. 44, pp. 32424-32432, 2007. 


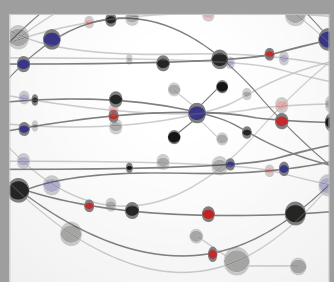

The Scientific World Journal
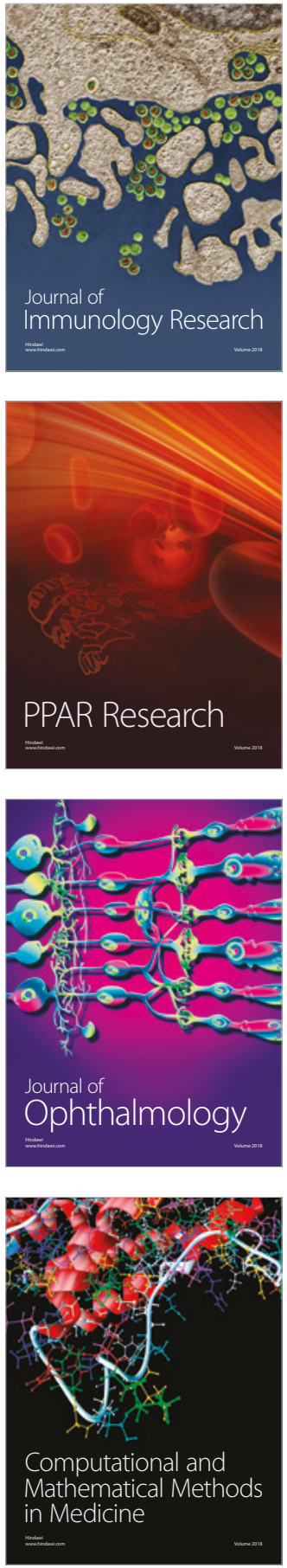

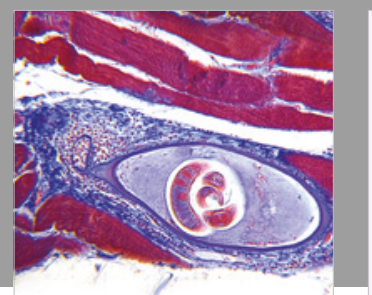

Gastroenterology Research and Practice

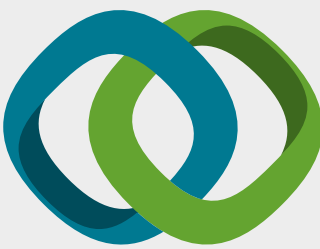

\section{Hindawi}

Submit your manuscripts at

www.hindawi.com
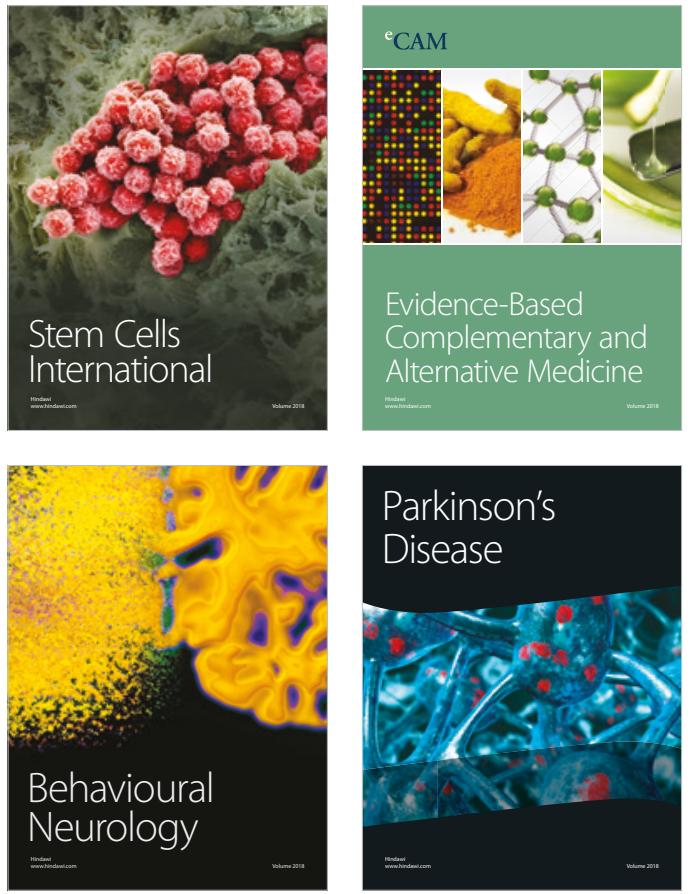

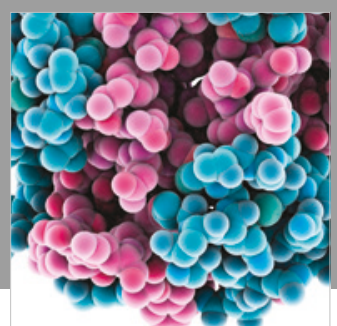

ournal of

Diabetes Research

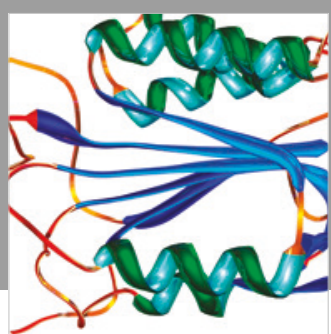

Disease Markers
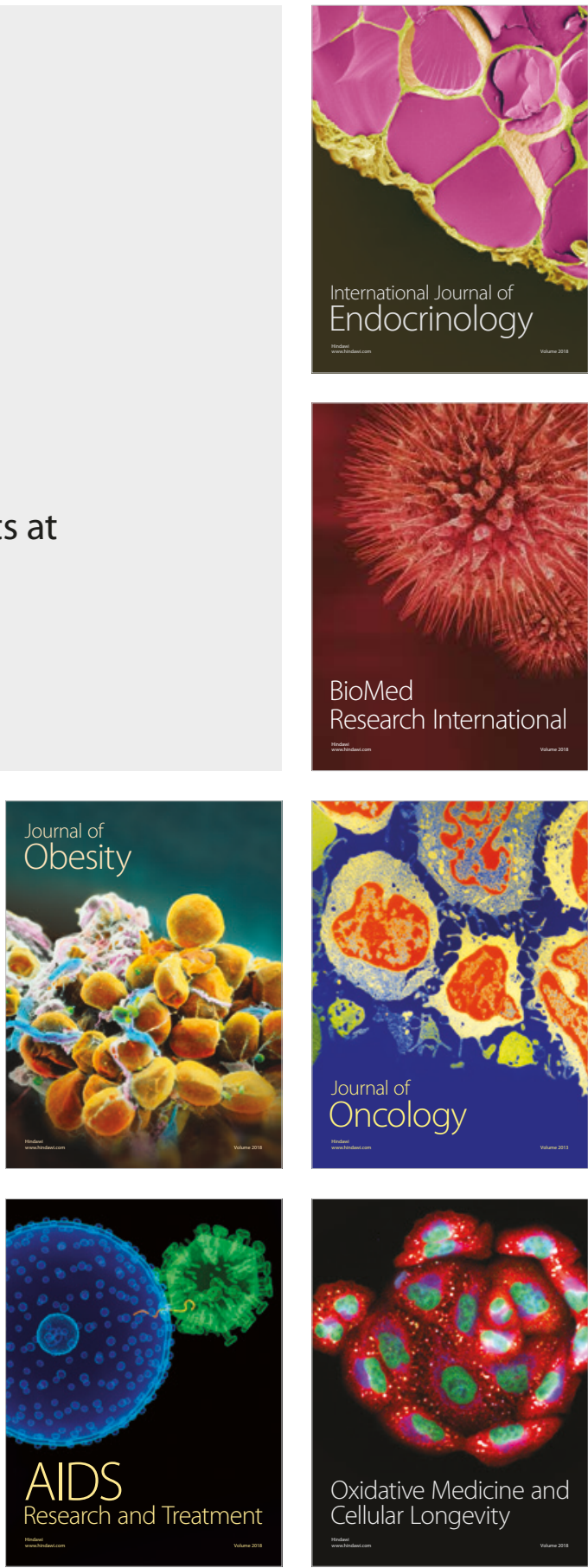